\title{
Infratentorial dural arteriovenous fistula resulting in brainstem edema and enhancement
}

\section{Figure $1 \quad$ MRI at presentation}

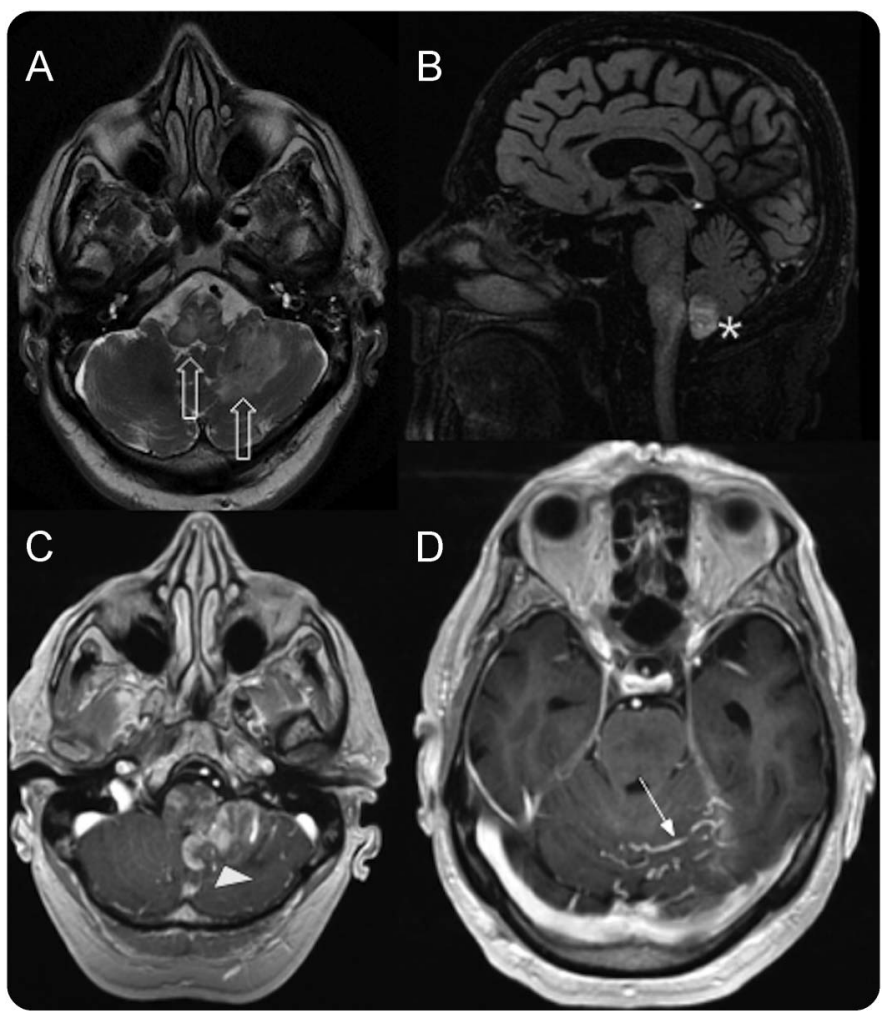

(A) T2-weighted image with hyperintensities in the brainstem and cerebellum (open arrows). (B) Sagittal fluid-attenuated inversion recovery shows swelling of cerebellar tonsil and hyperintensity (asterisk). (C) After gadolinium contrast, there is inhomogeneous enhancement of the hyperintense T2 areas (arrowhead). (D) Infratentorial extra-axial prominent vessels (arrow) are seen.

A 65-year-old man presented with a 2-year history of progressive eye movement abnormalities, bilateral limb weakness, and gait instability. MRI (figure 1) showed T2 hyperintensities in brainstem and cerebellum with enhancement, which were initially diagnosed as tumor. Closer inspection revealed prominent vascular structures at the tentorium. Digital subtraction angiography (DSA) showed an infratentorial dural arteriovenous fistula (DAVF) (figure 2). Following embolization with glue, the bilateral limb weakness improved and the other symptoms had resolved at discharge the next day.

Although DAVFs rarely have infratentorial localization, if MRI raises suspicion for it, DSA is the gold standard for diagnosis. ${ }^{1,2}$

Bart J. Emmer, MD, PhD, Adriaan C.G.M. van Es, MD, PhD, Peter J. Koudstaal, MD, PhD,

Stefan D. Roosendaal, MD, PhD

From Erasmus Medical Center (B.J.E., A.C.G.M.v.E., P.J.K.), Rotterdam; and Amsterdam Medical Center (S.D.R.), the Netherlands. Author contributions: Bart J. Emmer: acquisition of data and case description. Adriaan C.G.M. van Es: acquisition of data and critical review of manuscript. Peter J. Koudstaal: acquisition of data and critical review of manuscript. Stefan D. Roosendaal: acquisition of data and critical review of manuscript. 


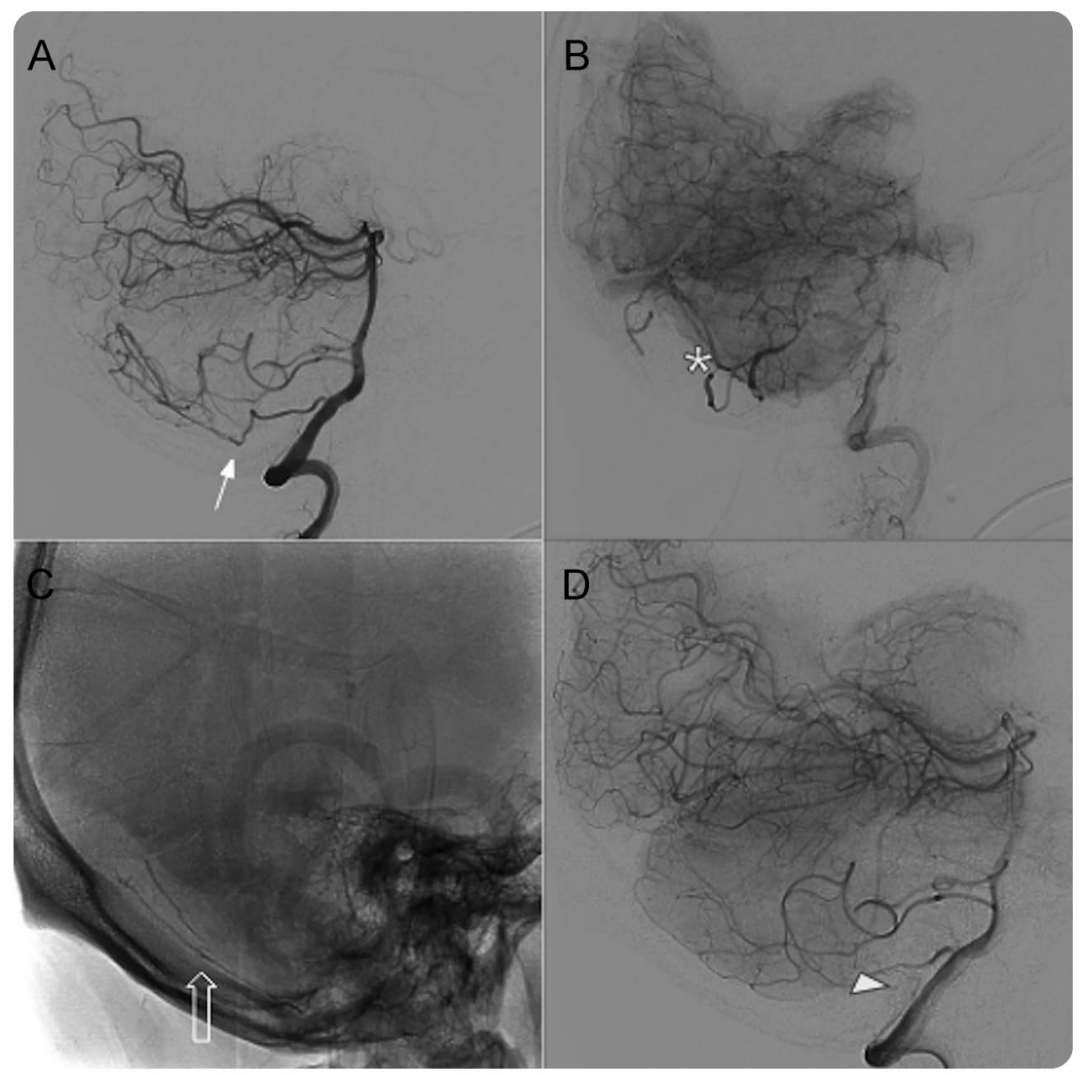

(A) Digital subtraction angiography of left vertebral artery with hypertrophic posterior meningeal artery (arrow) and early venous filling of cerebellar veins (asterisk) in (B). (C) N-butyl-2-cyanoacrylate glue cast (open arrow) after embolization. (D) Limited filling of posterior meningeal artery (arrowhead) and no residual shunting to venous structures in parenchymal phase after embolization.

Study funding: No targeted funding reported.

Disclosure: The authors report no disclosures relevant to the manuscript. Go to Neurology.org for full disclosures.

Correspondence to Dr. Emmer: b.emmer@erasmusmc.nl

1. Zhao J, Xu F, Ren J, Manjila S, Bambakidis NC. Dural arteriovenous fistulas at the craniocervical junction: a systematic review. J Neurointerv Surg 2016;8:648-653.

2. Alvarez H, Sasaki-Adams D, Castillo M. Resolution of brainstem edema after treatment of a dural tentorial arteriovenous fistula. Interv Neuroradiol 2015;21:603-608.

\section{Subspecialty Alerts by E-mail!}

Customize your online journal experience by signing up for e-mail alerts related to your subspecialty or area of interest. Access this free service by visiting Neurology.org/site/subscriptions/etoc.xhtml or click on the "E-mail Alerts" link on the home page. An extensive list of subspecialties, methods, and study design choices will be available for you to choose from-allowing you priority alerts to cutting-edge research in your field! 


\section{Neurology}

\section{Infratentorial dural arteriovenous fistula resulting in brainstem edema and enhancement}

Bart J. Emmer, Adriaan C.G.M. van Es, Peter J. Koudstaal, et al. Neurology 2017;88;503-504

DOI 10.1212/WNL.0000000000003569

This information is current as of January 30, 2017

\section{Updated Information \&} Services

References

Permissions \& Licensing

Reprints including high resolution figures, can be found at: http://n.neurology.org/content/88/5/503.full

This article cites 2 articles, 1 of which you can access for free at: http://n.neurology.org/content/88/5/503.full\#ref-list-1

Information about reproducing this article in parts (figures,tables) or in its entirety can be found online at:

http://www.neurology.org/about/about_the_journal\#permissions

Information about ordering reprints can be found online:

http://n.neurology.org/subscribers/advertise

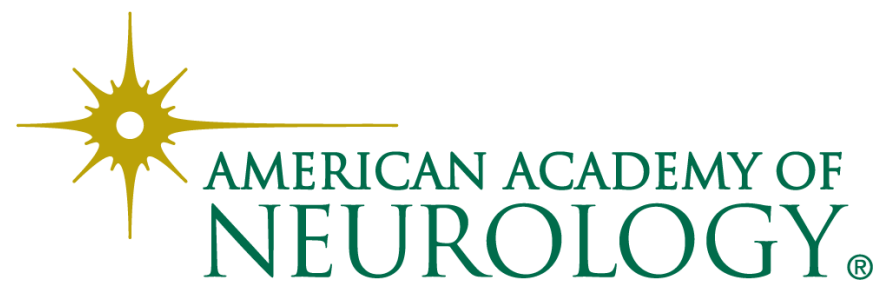

